\title{
Title: Predicting the presence and cover of management relevant invasive plant species on protected areas
}

Gwenllian Iacona $a^{a^{*}}$, gdiacona@gmail.com

Franklin D. Price ${ }^{b}$, fprice@admin.fsu.edu

Paul R. Armsworth ${ }^{a}$, p.armsworth@utk.edu

${ }^{a}$ Ecology and Evolutionary Biology

The University of Tennessee

569 Dabney Hall

Knoxville, TN 37996

U.S.A.

${ }^{b}$ Florida Natural Areas Inventory

1018 Thomasville Road, Suite 200-C

Tallahassee, Florida 32303 USA

* Corresponding author

Full contact details for corresponding author:

Gwen Iacona

Present address:

Centre for Excellence in Environmental Decisions

Room 523, Goddard Bldg 8, University Of Queensland,

ST LUCIA, QLD, 4072

Australia

Tel.: +61 (0) 424578995

Type of article: original research articles

Number of words in abstract: 266

Number of words in article: 3690

Number of references: 52

Number of Figures: 2

Number of Tables: 3 


\section{Abstract}

2 Invasive species are a management concern on protected areas worldwide.

3 Conservation managers need to predict infestations of invasive plants they aim to treat

4 if they want to plan for long term management. Many studies predict the presence of

5 invasive species, but predictions of cover are more relevant for management. Here we

6 examined how predictors of invasive plant presence and cover differ across species that

7 vary in their management priority. To do so, we used data on management effort and

8 cover of invasive plant species on central Florida protected areas. Using a zero-inflated

9 multiple regression framework, we showed that protected area features can predict the

10 presence and cover of the focal species but the same features rarely explain both.

11 There were several predictors of either presence or cover that were important across

12 multiple species. Protected areas with three days of frost per year or fewer were more

13 likely to have occurrences of four of the six focal species. When invasive plants were

14 present, their proportional cover was greater on small preserves for all species, and

15 varied with surrounding household density for three species. None of the predictive

16 features were clearly related to whether species were prioritized for management or

17 not. Our results suggest that predictors of cover and presence can differ both within

18 and across species but do not covary with management priority. We conclude that

19 conservation managers need to select predictors of invasion with care as species

20 identity can determine the relationship between predictors of presence and the more

21 management relevant predictors of cover.

\section{Keywords:}

conservation costs; Imperata cylindrica; Schinus terebinthifolius; Ludwigia peruviana; Lygodium microphyllum; Urena lobata

\section{Introduction}

Invasive plant control is a management cost on protected areas (PAs) worldwide (Frazee et al 2003; Goodman 2003; Reinhardt et al 2003; Pimentel et al 2005;

Pfennigwerth and Kuebbing 2012; Cleary 2013). Thus, predictions of invasion across

PAs are necessary to budget for long term management (Martin and Blossey 2012).

Such estimates contribute to regional scale conservation decisions (e.g. ranking sites for potential acquisition) yet, many of the current predictive models assume all invasive species are prioritized equally for management and predict species presence without considering cover (Pyšek et al 2002a;b; Foxcroft et al 2011). 
Conservation managers need estimates of both presence and cover. Predictions of presence are useful for identifying possible invaders and planning for monitoring (Catford et al 2012). Meanwhile, predictions of cover estimate the effort required to manage an invasion. However, few studies consider cover (Alston and Richardson 2006; Catford et al 2011; Polce et al 2011; Seabloom et al 2013), or how predictions of presence relate to cover (but see Kuhman et al 2010). This shortcoming hinders the application of existing studies to management.

Invasive plant species may co-occur on PAs, but they may not all be management priorities (Allen et al 2009; Kuebbing et al 2013; Abella 2014). Cost can constrain the management available at a PA (D'Antonio et al 2004; Tempel et al 2004), inducing managers to prioritize species that respond better to treatment. Alternatively, managers could aim to minimize invasive species impact and prioritize treatment of species that negatively affect species of conservation interest. Finally, managers may prioritize species that have historically been treated at the PA or whose management is specifically mandated in management plans (Pullin and Knight 2005). Regardless of why prioritization occurs, conservation planners need predictions of presence and cover that are robust across species that are a management priority.

The potential variation across predictors of presence, cover, and management priority, suggests that comparisons of invasion across species must consider three contrasts (Figure 1). The first contrast is an examination of predictor variables across species. The second contrast is the difference between predictors of presence and cover for a single species. The final is a comparison of shared predictors for species that are a high management priority (those that are likely to be treated) with shared predictors of species that are low management priority (and potentially inflating estimates of treatment need).

Previously, we related PA features to the proportional summed cover of the dominant invasive species on the PA (Iacona et al 2014). Our predictors of invasion included ecological attributes related to invasibility (Richardson 2011), and features related to human disturbance. The best predictors of the invadedness of a PA were PA size and the number of surrounding households (other variables tested include minimum temperature, road density, and elevation).

We now examine the relationship between PA-level features and the presence and cover of individual species that differ in management priority in central Florida. These species are noxious invaders according to the Florida Exotic Pest Plant Council (FLEPPC), and are documented as causing ecological harm (FLEPPC Category I invaders) or increasing in abundance or frequency within the state (Category II invaders). The FLEPPC categories roughly correspond with management priority in Florida and we tailor our choice of study species by drawing on management records. Variation in PA-level predictors of presence or cover is expected across species because of different life histories and distributions. However, we seek to understand variation within each species when predicting presence versus cover, and also whether predictors across species relate to their prioritization for management.

We expect PA features that predict the presence of a species to differ from those that predict cover. For instance, we expect the probability of presence to increase with 


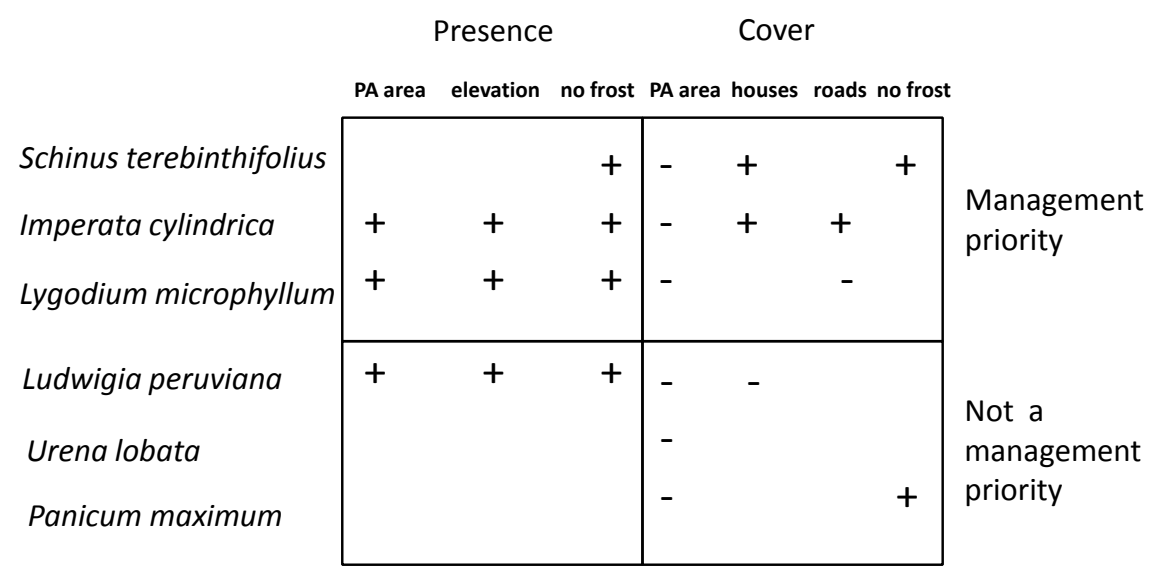

Figure 1: Diagram outlining study design and results. We examine the site-level features that predict the presence and cover of six different invasive plant species in Florida. These species were chosen based on their abundance and management priority. The sign in the table indicates the relationship described by significant predictors in the multiple regression models relating invasive presence and cover to site-level features. The predictive site-level features are listed along the top of the table. See Table 2 for model coefficient values.

PA size because of species area effects (McKinney 2002), with surrounding households because of human introductions (Gavier-Pizarro et al 2010), and with road density because of propagule transport (Von Der Lippe and Kowarik 2007). We also expect probability of presence to increase at lower latitudes (Marini et al 2009) because many of the species that are invasive in central Florida are frost sensitive. Finally, habitat type is likely to influence species presence (Chytrý et al 2008), so we include PA elevation as a proxy for broad habitat classes such as floodplain forest (low elevation), wet flatwood (medium elevation) or scrub (high elevation) (Myers and Ewel 1990). In contrast, we expect proportional cover to decrease with PA size, increase with household density, and potentially vary with winter temperature (Iacona et al 2014).

Predictive features may also be similar for species that are management priorities. For instance, PA size is a predictor that could relate to management priority if species that are more likely to be found on small PAs, because of disrupted ecological processes, are also more likely to be managed because they are obvious or noxious. Alternatively, species of management priority may be more likely on PAs close to human development because species that are introduced as ornamentals may be more likely to be invaders in natural areas than species that are agricultural pests (Richardson and Rejmnek 2011; Zenni 2014).

Here we develop models that concurrently predict presence and cover for six species that are prevalent on PAs in central Florida but differ in their priority for 
management. We ask:

1. Are predictors of presence and cover similar for a species?

2. Do predictors of presence and cover vary across species in relation to priority for management?

\section{Methods}

\subsection{Study system}

To address these questions we needed a comprehensive dataset of the relative abundance and treatment effort of invasive plants on PAs. There has been an extensive recent effort to quantify the extent of invasion on publicly-owned PAs within the state of Florida, USA (Cleary 2007) which provides an ideal study system. Florida is heavily impacted by invasion, and there are 159 species on the FLEPPC list of invasive plant species (FLEPPC list 2015, http://www.fleppc.org/list/list.htm). The more than 1800 publicly-owned PAs within the state range from temperate to tropical climates, urban to rural locations, and small to large area (Florida Natural Areas Inventory(FNAI), Florida Managed Areas (FLMA) database).

\subsection{Study species and sites}

For this study we selected six focal species, grouped according to priority for management, from the 159 FLEPPC listed species in the state. To do so, we examined the distribution of management effort across FLEPPC listed species using an operations database from the Florida Fish and Wildlife Conservation Commission (FWC) upland habitat management program (Cleary 2007). We calculated the proportion of effort applied to each species (by acreage or by number of individuals treated, depending on PA) to rank species by treatment effort (Supplementary Table SI1). We then used the ranking to choose the six study species highlighted in Figure 2. Schinus terebinthifolius (Brazilian pepper, introduced 1840 (Hight et al 2002)), Imperata cylindrica (cogon grass, introduced 1921 (Dozier et al 1998)), and Lygodium microphyllum (Old World climbing fern, introduced 1958 (Langeland and Hutchinson 2013)) are prioritized for treatment. Meanwhile, Ludwigia peruviana (Peruvian primrose-willow, introduced by 1877 (Kunzer, J., personal communication), Urena lobata (Caesar's weed, introduced 1897 (Austin 1999)), and Panicum maximum (Guinea grass, introduced 1933 (FNAI 2014)) are widely prevalent on public conservation lands but are a lower management priority. 


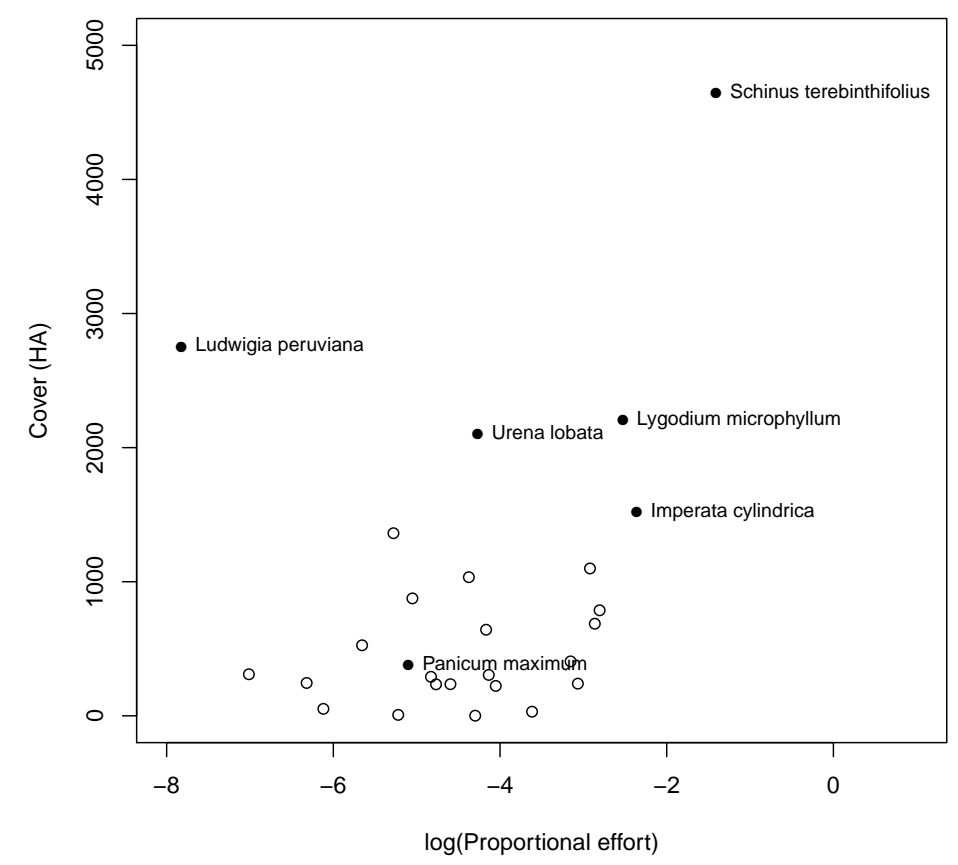

(a)

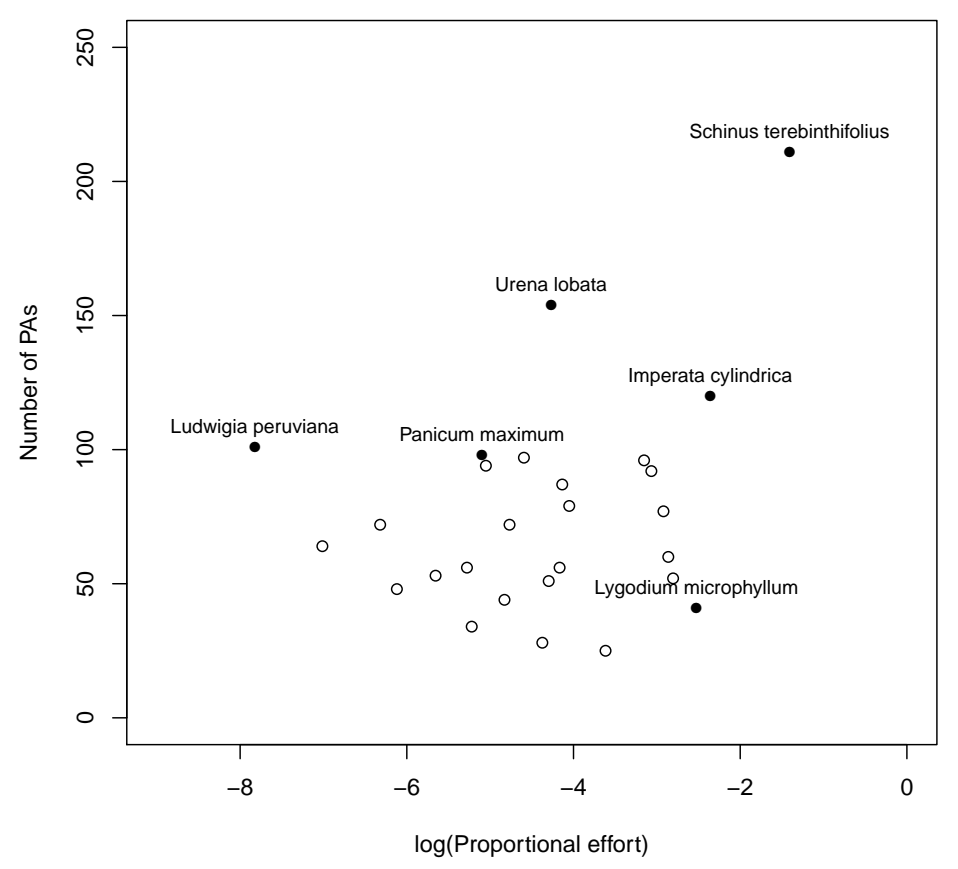

(b)

Figure 2: Variation in management effort and cover on protected areas (PAs) across the 28 species in our occurrence database (Supplementary Table 2). For this study we chose six focal species (filled circles) that differ in the amount of effort that is allocated to their treatment on PAs across Florida. This figure displays effort for each species in relation to (a) cover on 365 PAs and (b) the number of PAs it occurs on. Schinus terebinthifolius, Lygodium microphyllum and Imperata cylindrica are high priority species for management and also have high levels of cover across the state. Ludwigia peruviana, and Urena lobata are low priority for management but have high cover. Panicum maximum is a low priority for management but is present on many PAs. 
We obtained distribution data for these six species from the FLInv geodatabase. This database was commissioned by the Florida Fish and Wildlife Conservation Commission (FWC) to improve their prioritization of invasive species management funds and is maintained by the Florida Natural Areas Inventory (FNAI; database available at http://www.fnai.org/invasivespecies.cfm). Here we use the PA as the analysis replicate to represent regional decision making. We chose to use only records from PAs where data were collected by FNAI botanists between the years of 2008 and 2010 to standardize data collection protocols. We also chose PAs where all records for that species were GPS point data with surveyor-estimated area of coverage to improve the predictive capacity of our models (see Iacona et al 2014). The final dataset includes presence and absence information for six focal species on 365 PAs across Florida (Supplementary Information). Our criteria for species choice and data quality resulted in a sample of species that are primarily observed on PAs in central Florida. These PAs were slightly smaller (1st Q $=13.9 \mathrm{HA}$, Median $=62 \mathrm{HA}$, 3rd Q $=450 \mathrm{HA}$ ) than all the PAs in Florida (from FLMA dataset: 1st $\mathrm{Q}=15.42$, Median $=78 \mathrm{HA}$, 3rd Q $=$ $475 \mathrm{HA})$. While these records were a subset of the possible species and the entire network of PAs within the state, it was still a large sample spanning gradients of PA features. The limitations of this sample must be balanced against the desirability of having all surveys conducted by one agency with standardized reporting protocols.

\subsection{Protected area features}

We used predictive features that relate to the presence and cover of invasive species and that can be obtained from publicly available datasets. The first three factors relate to ecological function and community composition. PA size information was obtained from the FLMA dataset of PAs managed for conservation. We used elevation as a proxy for plant community type because, in Florida, very small changes in elevation correspond with obvious changes in vegetation (Myers and Ewel 1990), and it was a solution to the statistical challenge of adding community type as a categorical variable while still maintaining a balanced design. We derived PA average elevation from USGS NED $1 / 3$ arc second data layers at $1 \mathrm{~m}$ resolution. Winter PA temperature was represented by a binary variable (frost-bin) indicating three days of frost per year or not, as calculated from Daymet weather data for the state of Florida (Thornton et al 1997). The last two factors relate to anthropogenic disturbance at a PA. We estimated the number of nearby households by weighting the number of households in nearby year 2000 census-tracts by their overlap with a $25 \mathrm{~km}$ buffer around the PA. This buffer distance was chosen to account for the impacts of low density human development on invasion (Gavier-Pizarro et al 2010). We calculated road density as a proxy of onsite disturbance by dividing area of roads by PA size for all roads that intersected or were adjacent to the PA (USGS 24000:1 roads layer). We estimated average road width to be $10 \mathrm{~m}$ by assuming that two lane roads likely abut PAs. 


\subsection{Modeling approach}

Each species was present on only some of the 365 PAs (Supplementary Figure SI1) and we were interested in both the probability of occurrence of a species on a PA and its abundance if it was present. To model the two processes concurrently, we used a zero-inflated negative binomial model (Zeileis et al 2008) to predict expected proportional invasive cover at a PA in relation to PA features. We chose a negative binomial model because our observed variance in invasive plant cover was greater than the mean (overdispersion) and because AIC comparisons during the model-fitting process indicated that this error structure was the most appropriate.

Our modeling strategy considers the entire dataset to be binary data and models the probability of the species presence at a given PA, assuming a binomial distribution:

$$
\text { probability of presence }=\pi_{i}=1-\left(\frac{e^{\alpha+\beta_{1} X_{1 i}+\ldots \beta_{n} X_{n i}}}{\left(1+e^{\alpha+\beta_{1} X_{1 i}+\ldots \beta_{n} X_{n i}}\right.}\right)
$$

Here, $\alpha$ is the estimated model intercept and $\beta$ is the fitted coefficient for the site level factors $X_{i}$. Our model also uses the observed cover measurements and some of the zero cover records to relate the mean cover of a species at a PA to site-level features, assuming a negative binomial distribution:

$$
\text { mean cover if present }=\mu_{i}=e^{\alpha+\beta_{1} X_{1 i}+\ldots \beta_{n} X_{n i}}
$$

We can then calculate the expected value of the mean cover at a PA while accounting for the zero-inflated process (mean cover $=E\left(Y_{i}\right)=\mu_{i} * \pi_{i}$ ). This prediction of cover at a PA estimates expected cover weighted by the probability of the species being present.

To construct our response variable, we binned proportional cover for each species into thousandth of a percent bins to meet model assumptions of a discrete data distribution (Table 1). We constructed separate models for each of the six species using the pscl package in R (Zeileis et al 2008; R Development Core Team 2010; Jackman 2012). All models used a log link function to model the underlying proportional invasive cover distribution, and a logit link function to model the excess zeros. We log transformed all predictor variables, except frost-bin, to improve the model appropriateness for the observed distributions of individual predictors. There was moderate correlation between some predictor variables (e.g., negative correlation between frost bin and elevation), but none that exceeded acceptable thresholds for model assumptions (Dormann et al 2013). In addition, tolerance testing indicated that the variation explained by each of the predictor variables was not more than $20 \%$ 
dependent on variation in other predictor variables, ensuring that multicollinearity requirements were adequate to proceed (Quinn and Keough 2001). Finally, examination of semivariance plots of residuals from each model indicated that remaining spatial autocorrelation was not a concern in this analysis.

This zero-inflated modeling technique considers records of zero cover to be one of two types. If a species cover is zero it could be due to characteristics of the PA that precluded the species presence (e.g., outside its range of temperature tolerance), or it could be due to characteristics of the PA that relate to low amounts of cover (e.g., low propagule pressure minimizing establishment). Hence, we present the results in two sections even though they were produced in a single modeling process. The first describes the predictive features that relate to the probability that the species of interest is present at the PA. The second describes the predictive features that relate to the expected proportional cover of the species if it is present. For a prediction of expected invasive plant proportional cover for a species at a PA, multiply the estimated mean proportional cover (Table 2) by the probability of the PA having more than zero cover present (Table 3).

\section{Results}

Features that proxy for ecological characteristics were most important for predicting species presence in central Florida (Table 2). PAs with three frost days or fewer per year were more likely to have occurrences of $S$. terebinthifolius, L. peruviana, $I$. cylindrica, and L. microphyllum. In addition, the probability that I. cyclindrica, $L$. peruviana, and L. microphyllum were present increased as PA mean elevation increased. Meanwhile, PA features that relate to human disturbances were less important in predicting the presence of a species. Although I. cylindrica and $L$. microphyllum were more likely to be present as the PA size increased, households and roads were not significant predictors of presence for any tested species. Finally, no PA features predicted P. maximum or U. lobata presence.

In contrast, the PA-level features predicting proportional cover included both those that related to ecological characteristics and those that related to human disturbance (Table 3). The cover of all six species decreased as PA size increased. However, the species differed in their relationship to household density. $S$. terebinthifolius and I. cylindrica decreased in cover as the number of nearby households decreased while the cover of $L$. peruviana increased. Finally, $L$. microphyllum, P. maximum and $U$. lobata cover decreased as PA size increased but was not related to household density. In addition, frost-bin was a significant predictor of cover for S. terebinthifolius and P. maximum, with higher cover at PAs with three or fewer frost days per year. Road density was related to increased cover for I. cylindrica and decreased cover for L. microphyllum. 
Outliers were present in the models of each species, but we think the information provided by these highly invaded PAs was meaningful (very low proportional cover outliers were absorbed by the zero-inflated process). Therefore we present the results with all data included.

\section{Discussion}

This study examines how predictors of invasive plant cover and presence on PAs vary with species identity and management priority in central Florida. This approach is valuable from a conservation perspective because the fitted coefficients from models such as ours permit regional planners to estimate invasion across PAs, and thus management need, even if they only have information on PA features. For regional level planning, such predictive models are useful for coarse decisions - such as refining a list of potential acquisitions - and can postpone costly plant surveys. Here we find that predictive features differ for presence and cover within and across species, suggesting that predictions of presence and cover are not interchangeable. In addition, although we identify predictors that are important across multiple species, no predictors related to management priority species specifically.

There are many possible metrics of invasion (Richardson 2011), but we have chosen to focus on presence and cover because of their management relevance. Predictors of the presence of a species were often quite different than predictors of cover in central Florida. For instance, in several models, the probability of presence of a species increased with PA size, but the proportional cover decreased. This result suggests that the two factors respond differently to site area and reinforces the call for predictions of cover as well as presence for management applications (Catford et al 2012; Bradley 2013; Seabloom et al 2013).

The conservation implications of this discrepancy are relevant for management. For instance, some species can be managed to minimize presence on PAs, such as when the early detection and response to L. microphyllum is prioritized on the invasion front in central Florida (Hutchinson et al 2006). Meanwhile other species are managed to minimize cover, such as Melaleuca quinquenervia in the Florida Everglades 2014, CISRERP. Notably, predictors of presence tended to be features related to ecological characteristics. In contrast, the proportional cover of the species was more often related to features that indicated human disturbance on a PA.

\section{Specific PA-level predictors of presence and cover are important if a planner} wants to plan for management of one of our six study species. However, several predictive features were common across many of the models, and we suggest that those predictors could be appropriate for modeling invadedness of a PA regardless of species. Across species in central Florida, the most important predictor of presence was whether there were three or fewer frost days per year at the PA. Meanwhile, for 
estimates of cover, these factors were PA size and the number of houses within $25 \mathrm{~km}$ of the PA. When interpreting these results, it should be observed that our models were parameterized on a subset of PAs that excluded the very largest sites. We suggest that extrapolating our results to the very largest PAs (e.g. the 6 PAs in Florida that are larger than 100,000 HA) should be done with caution.

Finally, we show that invasion by species of high management priority in central Florida is not predicted by different features than those that are low management priority. Instead, both presence and cover of all six of our focal species were related to slightly different factors. These associations were reasonable based on the physiology and life history of the individual species, as we discuss in section 4.1 below, but there was no clear grouping of factors related to management priority.

\subsection{Species specific results}

\subsubsection{High management priority species}

Schinus terebinthifolius is a documented management priority in peninsular Florida (Cuda et al 2006). It is found on the most PAs throughout the state, covers the most area, and is allocated the most effort and funding of species that are treated in Florida (Supplementary Table SI1). It is range restricted in Florida and its presence at a PA was almost entirely related to frost free days. However, on PAs where the species was present, the proportional cover of $S$. terebinthifolius decreased as PA size increased, as household density decreased, and when there were more than three days with frost.

Imperata cylindrica is also a management priority in Florida. Our model suggests that its proportional cover is correlated with road density. This is not surprising because $I$. cylindrica is a perennial rhizomatous grass that is primarily vegetatively dispersed (Dozier et al 1998). The species is common along roadsides, as the rhizomes are often transported in road fill and by grading equipment (Jose et al 2002). In addition, the positive relationship between the presence of $I$. cylindrica and elevation is reasonable because this species is able to tolerate hot, dry conditions and is one of the few species that will invade upland pine (Yager et al 2010) and scrub communities.

The presence of Lygodium microphyllum was positively related to elevation. This may be related to its prevalence on large inland PAs in central Florida (Ferriter and Pernas 2006). Its proportional cover also decreased with increased road cover. This could be because, as a statewide management priority (Hutchinson et al 2006), it is likely to be intensively treated in accessible areas. However, these results should be interpreted with care because this species was present on only 18 PAs in our study and our data selection criteria excluded several of the largest parks in south Florida where this species is a primary pest. 
Our model suggests that the proportional cover of Ludwigia peruviana decreases with proximity to human households. This wetland species is prevalent in large, shallow wetlands produced by water control projects in south Florida (Toth 2010). These wetlands may be less common in developed areas. In addition, the probability of presence of L. peruviana is positively related to elevation. This seems counterintuitive for a wetland species, but if it prefers the types of wetlands that are present in the interior of the state, where there is higher elevation and greater distance from the human development along the coast, both patterns would hold.

Finally, the presence of both Panicum maximum and Urena lobata was not strongly related to PA features. In addition, the proportional cover of neither of these species was well explained by the density of surrounding households, although they both did decrease in cover as PA size increased. This is probably because both are common ruderal species, with near ubiquitous presence on PAs in central Florida (Austin 1999).

\subsection{Extensions}

We were particularly interested in features that predicted invasion across species of management interest. However, it would be possible to refine the model to further explore drivers behind species specific patterns, for instance PA area and access and $L$. microphyllum. In addition, we did not find common site-level predictors across species with similar management priority, but it is possible that other characteristics of these species could meaningfully predict their presence and cover. For instance, time since invasion is a species characteristic that could correlate with management priority. Finally, one important potential predictor that we do not include in our models is a measure of how much effort has been allocated to management at the site. There is highly resolved cost data available for many of these PAs (Iacona et al 2014). However, the invasion data is from a single sampling time and the relationship between observed invasion and spend can go both ways (spending is higher at sites with more invasion, but higher spending should reduce invasion). This endogeneity problem limits the scope for including these data in our current models.

\subsection{Conclusions}

Invasive plant species management is often a priority for biodiversity conservation, and we confirm that species identity can be important from a planning perspective. Our work suggests that certain PA features robustly predict presence and cover across species, at least in central Florida, but that these predictors are not clearly related to 


\subsection{Acknowledgments}

355 We would like to thank R. Cleary at FWC for data, and T. Martin at CSIRO for

management priority. If such predictions are intended for conservation decision making at a regional scale (e.g. if assessing the possible consequences of pursuing agency-wide policies on minimum reserve sizes), it is important to understand the variation in network wide trends of presence and proportional cover. In such cases, a model such as ours, that uses cheap, easily obtainable coarse grain data to predict expected variation in presence and cover at the scale of a PA would be appropriate. statistical assistance. GI was supported by the National Institute for Mathematical and Biological Synthesis, an institute sponsored by the National Science Foundation, the U.S. Department of Homeland Security, and the U.S. Department of Agriculture through NSF Award \#EF-0832858, with additional support from UTK department of Ecology and Evolutionary Biology and the ARC Center of Excellence for Environmental Decisions. We are also grateful to members of the Armsworth lab, S. Wiggers, S. Kuebbing, D. Simberloff, L. Gross, D. Hodges, and anonymous reviewers for helpful comments on earlier versions of this manuscript. 


\section{References}

Abella SR (2014) Effectiveness of exotic plant treatments on national park service lands in the United States. Invasive Plant Science and Management 7(1):147-163

Allen JA, Brown CS, Stohlgren TJ (2009) Non-native plant invasions of United States National Parks. Biological Invasions 11(10):2195-2207

Alston KP, Richardson DM (2006) The roles of habitat features, disturbance, and distance from putative source populations in structuring alien plant invasions at the urban/wildland interface on the Cape Peninsula, South Africa. Biological Conservation 132:183-198

Austin D (1999) Caesar's weed (Urena lobata) - an invasive exotic, or a Florida native? Wildland Weeds Winter:13-16

Bradley B (2013) Distribution models of invasive plants over-estimate potential impact. Biological Invasions 15(7):1417-1429

Catford JA, Vesk PA, White MD, Wintle BA (2011) Hotspots of plant invasion predicted by propagule pressure and ecosystem characteristics. Diversity and Distributions 17(6):1099-1110

Catford JA, Vesk PA, Richardson DM, Pyek P (2012) Quantifying levels of biological invasion: towards the objective classification of invaded and invasible ecosystems. Global Change Biology 18(1):44-62

Chytrý M, Jarosík V, Pyšek P, Hájek O, Knollová I, Tichý L, Danihelka J (2008) Separating habitat invasibility by alien plants from the actual level of invasion. Ecology 89(6):1541-1553

Cleary RL (2007) Controlling upland invasive exotic plants on public conservation land: a strategic plan. Natural Areas Journal 27(3):218-225

Cleary RL (2013) A comparitive analysis of state programs and funding for terrestrial invasive plant control. Tech. rep., Florida Fish and Wildlife Conservation Commission, upland invasive plant management program

Committee on independent scientific review of Everglades restoration progress (2014) Progress toward restoring the everglades: The fifth biennial review, 2014. Tech. rep., The National Academies Press

Cuda J, Ferriter A, Manrique V, Medal J (2006) Interagency Brazilian peppertree (Schinus terebinthifolius) management plan for Florida. Tech. rep., Florida Exotic Pest Plant Council

D’Antonio CM, Jackson NE, Horvitz CC, Hedberg R (2004) Invasive plants in wildland ecosystems: merging the study of invasion processes with management needs. Frontiers in Ecology and the Environment 2(10):513-521 
Dormann CF, Elith J, Bacher S, Buchmann C, Carl G (2013) Collinearity: a review of methods to deal with it and a simulation study evaluating their performance. Ecography (Copenhagen) 36(1):27-46, DOI 10.1111/j.1600-0587.2012.07348.x

Dozier H, Gaffney JF, McDonald SK, Johnson ERRL, Shilling DG (1998) Cogongrass in the United States: history, ecology, impacts, and management. Weed Technology 12(4):737-743

Ferriter A, Pernas T (2006) An explosion in slow motion: tracking the spread of Lygodium microphyllum in Florida. Wildland Weeds Spring 2006:7-9

FNAI (2014) Panicum maximum. URL http://fnai.org/invasives/panicum_maximum_fnai.pdf

Foxcroft LC, Jarošík V, Pyšek P, Richardson DM, Rouget M (2011) Protected-area boundaries as filters of plant invasions. Conservation Biology 25(2):400-405

Frazee SR, Cowling RM, Pressey RL, Turpie JK, Lindenberg N (2003) Estimating the costs of conserving a biodiversity hotspot: a case-study of the Cape Floristic Region, South Africa. Biological Conservation 112(12):275-290

Gavier-Pizarro GI, Radeloff VC, Stewart SI, Huebner CD, Keuler NS (2010) Housing is positively associated with invasive exotic plant species richness in New England, USA. Ecological Applications 20(7):1913-1925

Goodman PS (2003) Assessing management effectiveness and setting priorities in protected areas in KwaZulu-Natal. Bioscience 53(9):843-850

Hight S, Cuda J, Medal J (2002) Brazilian peppertree. in: Biological control of invasive plants in the eastern united states. Report, United States Department of Agriculture Forest Service. Forest Health Technology Enterprise Team

Hutchinson J, Ferriter A, Serbesoff-King K, Langeland K, Rodgers L (2006) Old weverorld climbing fern (lygodium microphyllum) management plan for Florida. Tech. rep., Florida Exotic Pest Plant Council, Lygodium Task Force

Iacona GD, Price FD, Armsworth PR (2014) Predicting the invadedness of protected areas. Diversity and Distributions 20(4):430-439

Jackman S (2012) pscl: Classes and methods for R developed in the political science computational laboratory, stanford university

Jose S, Cox J, Miller DL, Schilling DG, Merrit S (2002) Alien plant invasions: the story of cogongrass in southeastern forests. Journal of Forestry 100(1):41-44

Kuebbing SE, Nuñez MA, Simberloff D (2013) Current mismatch between research and conservation efforts: the need to study co-occurring invasive plant species. Biological Conservation 160(0):121-129 
Kuhman TR, Pearson SM, Turner MG (2010) Effects of land-use history and the contemporary landscape on non-native plant invasion at local and regional scales in the forest-dominated southern appalachians. Landscape Ecology 25(9):1433-1445

Langeland K, Hutchinson J (2013) Natural area weeds: Old world climbing fern (lygodium microphyllum). Report, University of Florida IFAS Extension

Marini L, Gaston KJ, Prosser P, Hulme PE (2009) Contrasting response of native and alien plant species richness to environmental energy and human impact along alpine elevation gradients. Global Ecology and Biogeography 18:652-661

Martin LJ, Blossey B (2012) Invasive plant cover impacts the desirability of lands for conservation acquisition. Biodiversity and Conservation 21(8):1987-1996

McKinney ML (2002) Influence of settlement time, human population, park shape and age, visitation and roads on the number of alien plant species in protected areas in the usa. Diversity and Distributions 8:311-318

Myers RL, Ewel J John (1990) Ecosystems of Florida. University of Central Florida Press, Orlando

Pfennigwerth AA, Kuebbing SE (2012) Direct costs associated with invasive non-native plants in Tennessee. Wildland Weeds 15(3-4):4-6

Pimentel D, Zuniga R, Morrison D (2005) Update on the environmental and economic costs associated with alien-invasive species in the United States. Ecological Economics 52(3):273-288

Polce C, Kunin WE, Biesmeijer JC, Dauber J, Phillips OL, The Alarm Field Site Network (2011) Alien and native plants show contrasting responses to climate and land use in europe. Global Ecology and Biogeography 20(3):367-379

Pullin AS, Knight TM (2005) Assessing conservation management's evidence base: a survey of management-plan compilers in the United Kingdom and Australia. Conservation Biology 19(6):1989-1996

Pyšek P, Jarošík V, Kučera T (2002a) Patterns of invasion in temperate nature reserves. Biological Conservation 104(1):13-24

Pyšek P, Kučera T, Jarošík V (2002b) Plant species richness of nature reserves: the interplay of area, climate and habitat in a central european landscape. Global Ecology and Biogeography 11(4):279-289

Quinn G, Keough MJ (2001) Experimental design and data analysis for biologists. Cambridge University Press, Cambridge

R Development Core Team (2010) R: a language and environment for statistical computing 
Reinhardt F, Herle M, Bastiansen F, Streit B (2003) Economic impact of the spread of alien species in Germany. Tech. rep., J.W. Goethe-University Frankfurt/Main Biological and Computer Sciences Division Department of Ecology and Evolution

Richardson DM (2011) Fifty years of invasion ecology: the legacy of Charles Elton. Wiley-Blackwell, Chichester

Richardson DM, Rejmnek M (2011) Trees and shrubs as invasive alien species a global review. Diversity and Distributions 17(5):788-809

Seabloom E, Borer ET, Buckley Y, Cleland WE, Davies K, Firn J, Harpole WS, Hautier Y, Lind E, MacDougall A, Orrock JL, Prober SM, Adler P, Alberti J, Anderson TM, Bakker JD, Biederman LA, Blumenthal D, Brown CS, Brudvig LA, Caldeira M, Chu C, Crawley MJ, Daleo P, Damschen EI, D’Antonio CM, DeCrappeo NM, Dickman CR, Du G, Fay PA, Frater P, Gruner DS, Hagenah N, Hector A, Helm A, Hillebrand H, Hofmockel KS, Humphries HC, Iribarne O, Jin VL, Kay A, Kirkman KP, Klein JA, Knops JMH, La Pierre KJ, Ladwig LM, Lambrinos JG, Leakey ADB, Li Q, Li W, McCulley R, Melbourne B, Mitchell CE, Moore JL, Morgan J, Mortensen B, O'Halloran LR, Prtel M, Pascual J, Pyke DA, Risch AC, Salguero-Gmez R, Sankaran M, Schuetz M, Simonsen A, Smith M, Stevens C, Sullivan L, Wardle GM, Wolkovich EM, Wragg PD, Wright J, Yang L (2013) Predicting invasion in grassland ecosystems: is exotic dominance the real embarrassment of richness? Global Change Biology 19(12):3677-3687

Tempel DJ, Gilimburg AB, Wright V (2004) The status and management of exotic and invasive species in national wildlife refuge wilderness areas. Natural Areas Journal 24(4):300-306

Thornton P, Running S, White M (1997) Generating surfaces of daily meteorological variables over large regions of complex terrain. Journal of Hydrology 190:214-251, URL http://dx.doi.org/10.1016/S0022-1694(96)03128-9

Toth LA (2010) Unrealized expectations for restoration of a floodplain plant community. Restoration Ecology 18(6):810-819

Von Der Lippe M, Kowarik I (2007) Long-distance dispersal of plants by vehicles as a driver of plant invasions. Conservation Biology 21(4):986-996

Yager LY, Miller DL, Jones J (2010) Susceptibility of longleaf pine forest associations in south Mississippi to invasion by cogongrass [imperata cylindrica (1.) beauv.]. Natural areas journal 30(2):226-232

Zeileis A, Kleiber C, Jackman S (2008) Regression models for count data in R. Journal of Statistical Software 27(8):URL http://www.jstatsoft.org/v27/i08/.

Zenni RD (2014) Analysis of introduction history of invasive plants in Brazil reveals patterns of association between biogeographical origin and reason for introduction. Austral Ecology 39(4):401-407 
Table 1: Descriptive statistics. Our response variable is the proportional cover of the six study species. This value is the total cover for each species at a protected area (PA) divided by the size of the PA. The number of study PAs (n) with cover data varies with species. Total area (hectares $=$ HA) invaded describes the sum of cover for each species across the 365 study PAs. Proportional effort indicates the relative proportion of management activity allocated to each species between 1999 and 2009 (see Supplementary Table SI1 for more information). The predictor variables were site level features of PAs

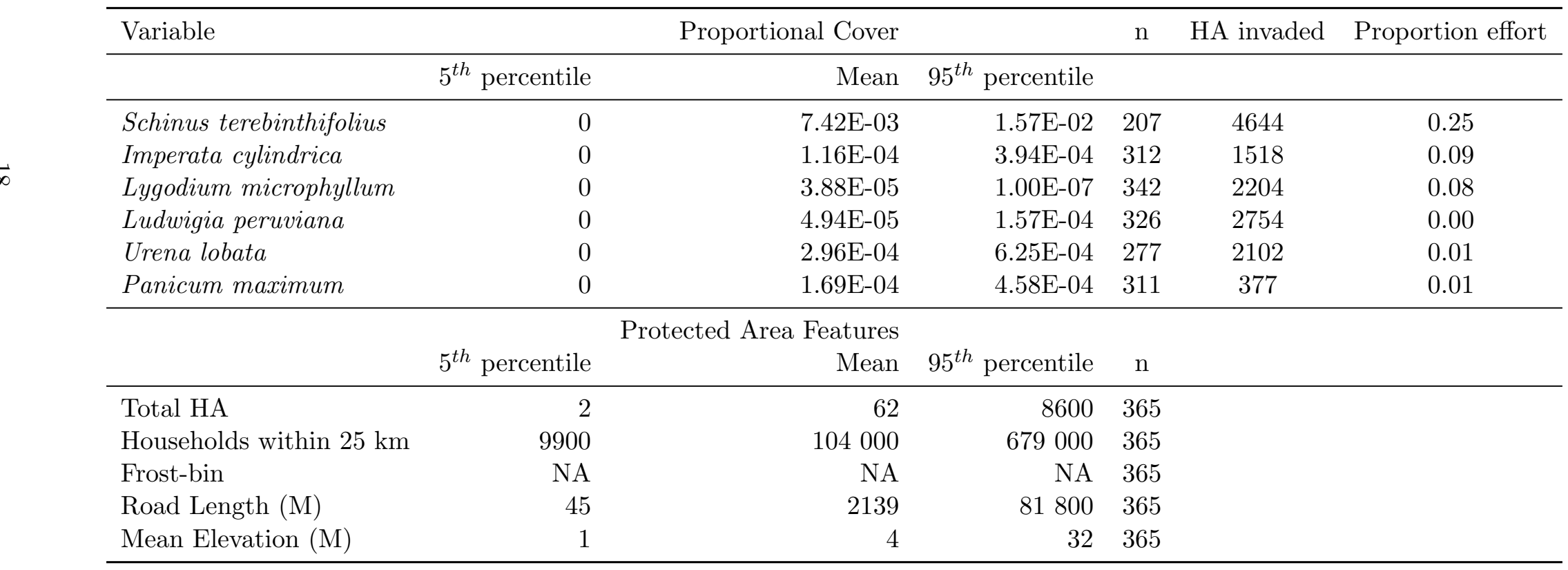


Table 2: Parameter estimates and standard errors (Coefficient $\pm 1 \mathrm{SE}$ ) for the model component that predicts the presence of an invasive species on a protected area. The probability that a species is present at a protected area is calculated as 1 minus the logit of the linear combination of these coefficients multiplied by the predictor variable values for that protected area. See text in section 2.4 for the equation. Values in bold font are statistically significant at $\mathrm{p} \leq 0.05$.

\begin{tabular}{lrrrrrr}
\hline & Intercept & $\log$ HA & $\log$ house density & $\log$ road cover & $\log$ elevation & frost-bin \\
\hline Schinus terebinthifolius & $-11.65 \pm 8.52$ & $-0.06 \pm 0.25$ & $1.15 \pm 0.68$ & $-0.18 \pm 0.11$ & $0.76 \pm 0.58$ & $\mathbf{- 2 . 6 9} \pm \mathbf{1 . 1 7}$ \\
Imperata cylindrica & $-4.29 \pm 5.75$ & $\mathbf{- 0 . 7 0} \pm \mathbf{0 . 1 9}$ & $0.26 \pm 0.28$ & $0.45 \pm 0.29$ & $\mathbf{- 0 . 8 6} \pm \mathbf{0 . 2 8}$ & $\mathbf{- 1 . 4 6} \pm \mathbf{0 . 6 5}$ \\
Ludwigia peruviana & $12.34 \pm 4.71$ & $\mathbf{- 0 . 6 8} \pm \mathbf{0 . 1 7}$ & $-0.55 \pm 0.35$ & $-0.05 \pm 0.07$ & $\mathbf{- 0 . 9 4} \pm \mathbf{0 . 3 3}$ & $\mathbf{- 1 . 6 0} \pm \mathbf{0 . 7 2}$ \\
Lygodium microphyllum & $13.72 \pm 6.32$ & $\mathbf{- 1 . 1 3} \pm \mathbf{0 . 3 3}$ & $0.00 \pm 0.43$ & $0.10 \pm 0.09$ & $\mathbf{- 1 . 4 2} \pm \mathbf{0 . 5 8}$ & $\mathbf{- 7 . 2 5} \pm \mathbf{2 . 7 5}$ \\
Panicum maximum & $6.33 \pm 4.54$ & $-0.56 \pm 0.31$ & $0.06 \pm 0.36$ & $-0.32 \pm 0.21$ & $0.69 \pm 0.39$ & $-0.98 \pm 0.94$ \\
Urena lobata & $-14.51 \pm 48.45$ & $-1.29 \pm 0.78$ & $0.89 \pm 0.72$ & $-1.10 \pm 1.00$ & $-3.85 \pm 1.97$ & $26.49 \pm 50.29$ \\
\hline
\end{tabular}


Table 3: Parameter estimates and standard errors (Coefficient $\pm 1 \mathrm{SE}$ ) for the model component that predicts proportion invasive cover of an invasive species at a protected area if the species is present. The mean proportion invasive cover at a protected area follows a binomial distribution and thus is calculated as $\exp ($ the linear combination of these coefficients multiplied by the predictor variable values for that protected area). See text in section 2.4 for the equation. Values in bold font are statistically significant at $\mathrm{p} \leq 0.05$.

\begin{tabular}{lrrrrrrr}
\hline & Intercept & $\log$ HA & log house density & log road cover & $\log$ elevation & frost-bin & dispersion \\
\hline Schinus terebinthifolius & $-5.16 \pm 3.26$ & $\mathbf{- 0 . 5 8} \pm \mathbf{0 . 2 1}$ & $\mathbf{0 . 7 1} \pm \mathbf{0 . 2 6}$ & $-0.11 \pm 0.08$ & $0.00 \pm 0.44$ & $\mathbf{4 . 6 8} \pm \mathbf{0 . 9 7}$ & $5.34 \pm 1.17$ \\
Imperata cylindrica & $-11.17 \pm 3.67$ & $\mathbf{- 0 . 3 3} \pm \mathbf{0 . 0 9}$ & $\mathbf{0 . 4 0} \pm \mathbf{0 . 2 0}$ & $\mathbf{0 . 6 0} \pm \mathbf{0 . 1 8}$ & $-0.07 \pm 0.16$ & $0.42 \pm 0.38$ & $1.26 \pm 0.41$ \\
Ludwigia peruviana & $11.51 \pm 5.38$ & $\mathbf{- 0 . 5 1} \pm \mathbf{0 . 1 0}$ & $\mathbf{- 0 . 5 6} \pm \mathbf{0 . 2 9}$ & $-0.19 \pm 0.19$ & $-0.15 \pm 0.19$ & $0.70 \pm 0.47$ & $2.08 \pm 0.71$ \\
Lygodium microphyllum & $10.77 \pm 5.66$ & $\mathbf{- 0 . 6 9} \pm \mathbf{0 . 2 0}$ & $-0.22 \pm 0.41$ & $\mathbf{- 0 . 2 2} \pm \mathbf{0 . 0 6}$ & $-0.48 \pm 0.37$ & $-0.90 \pm 2.80$ & $0.52 \pm 0.63$ \\
Panicum maximum & $8.60 \pm 4.67$ & $\mathbf{- 0 . 7 3} \pm \mathbf{0 . 1 7}$ & $-0.41 \pm 0.35$ & $-0.15 \pm 0.29$ & $0.28 \pm 0.46$ & $\mathbf{2 . 3 2} \pm \mathbf{0 . 8 6}$ & $3.75 \pm 2.36$ \\
Urena lobata & $-1.86 \pm 2.82$ & $\mathbf{- 0 . 4 6} \pm \mathbf{0 . 0 9}$ & $0.41 \pm 0.21$ & $-0.09 \pm 0.08$ & $0.22 \pm 0.21$ & $0.95 \pm 0.56$ & $6.41 \pm 1.21$ \\
\hline
\end{tabular}

